\title{
Peripheral biomarkers for pediatric brain tumors: current advancements and future challenges
}

\author{
Markus J. Bookland ${ }^{1,2}$, Antonina Kolmakova ${ }^{2}$ \\ 'Division of Neurosurgery, Connecticut Children's Medical Center, Hartford, CT 06106, USA. \\ ${ }^{2}$ Department of Pediatrics, University of Connecticut Health Center, Farmington, CT 06106, USA.
}

Correspondence to: Dr. Markus J. Bookland, Division of Neurosurgery, Connecticut Children's Medical Center, 282 Washington St., Hartford, CT 06106, USA. E-mail: mbookland@connecticutchildrens.org

How to cite this article: Bookland MJ, Kolmakova A. Peripheral biomarkers for pediatric brain tumors: current advancements and future challenges. J Cancer Metastasis Treat 2019;5:33. http://dx.doi.org/10.20517/2394-4722.2018.110

Received: 30 Dec 2018 First Decision: 26 Feb 2019 Revised: 16 Mar 2019 Accepted: 21 Mar 2019 Published: 19 Apr 2019

Science Editor: Bingliang Fang Copy Editor: Cai-Hong Wang Production Editor: Huan-Liang Wu

\begin{abstract}
Circulating biomarkers - nucleic acids, proteins, and metabolites - have been used in several adult oncologic processes to affect early detection, measure response to treatment, and offer prognostic information. The identification and validation of biomarkers for pediatric brain tumors, however, has been meager by comparison. Early detection and serial screening of pediatric brain tumors has the potential to improve outcomes by allowing for rapid therapeutic interventions and more targeted therapies. This is particular resonant for pediatric brain tumors where treatment success is heavily dependent on early surgical intervention. This highlights the need for biomarker development in pediatric neuro-oncology. The authors reviewed current circulating biomarker targets in various biofluid reservoirs and discuss the current barriers to biomarker development in pediatric neuro-oncology patients.
\end{abstract}

Keywords: Pediatric, brain tumor, biomarker, miRNA, biofluid, overview

\section{INTRODUCTION}

Pediatric brain tumors are the leading, oncologic cause of death in children under 10 in North America. Roughly 4,600 children are diagnosed with brain tumors every year in the United States, and maximal, safe surgical resection remains the primary treatment modality ${ }^{[1-3]}$. Five-year survivals can vary by as much as $70 \%$ with some of the most common pediatric brain tumors, depending on a surgeon's ability to achieve complete safe resection of the mass ${ }^{[4-8]}$. This makes early diagnosis and intervention, potentially, critical to

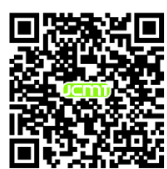


ensuring favorable outcomes, as surgical resection is generally more successful when tumors are smaller, confined to a single location, and less entwined with critical neural structures.

Despite a general awareness of the importance of establishing a prompt diagnosis for pediatric brain tumor care, delay in time to diagnosis is common with pediatric brain tumor patients, as children have a unique capacity to tolerate intracranial volume and pressure changes with minimal outward symptoms ${ }^{[0]}$. Additionally, the immature nature of the nervous system in infants makes clinical screening for brain tumor-related symptoms challenging. Widespread radiographic screening of children, be it with computed tomography or magnetic resonance imaging, is impractical due to the risks of radiation exposure to the developing central nervous system, neurotoxic effects of early anesthetic exposure, and prohibitive diagnostic $\operatorname{costs}^{[10-12]}$.

As such, a minimally invasive, reliable, and cheaply implemented screening tool has become a great clinical need for physicians and researchers seeking to improve early tumor detection, develop minimally invasive methods for molecular stratification of tumors, and allow for reliable post-treatment screening in pediatric brain tumor populations. Numerous permutations exist for researchers seeking to discover and validate novel biomarkers, as potential tumor markers need to be examined in different biofluid reservoirs and with different analytic techniques. Each variation in biomarker sampling and analysis exposes different advantages and limitations that researchers and clinicians must be cognizant of as they search for accurate and realistically deployable brain tumor biomarker assays. The authors will review here the history of biomarker development for pediatric brain tumors to date, the limitations and advantages of current target biofluids, promising biomarkers for the most prevalent pediatric brain tumors, and the major limitations of biomarker development in pediatric populations.

\section{Historical biomarkers}

Attempts to acquire objective evidence of a tumor from extra-tumor biofluids date back at least 100 years, beginning with cerebrospinal fluid (CSF) cytology. Tumor cytology is the oldest and most well-understood method for detecting and differentiating pediatric brain tumors via a biofluid ${ }^{[13]}$. The use of cytology to diagnose tumors in a minimally invasive manner dates back to the 19th century ${ }^{[14]}$. The process for acquiring CSF samples for cytologic analysis has the benefit of being relatively simple to perform and widely available in most regions of the world. In order to acquire a CSF sample, a lumbar puncture is performed with a sterile 20-22-gauge needle at or below the L2/L3 interlaminar space. Ventricular CSF samples have been used, as well, for CSF cytology; but the sensitivity of samples acquired from cerebral ventricular punctures is significantly lower than samples drawn from the lumbar cistern, likely due to sedimentation of tumor cells into the dependent lumbar cistern ${ }^{[15]}$. CSF samples are then fixed and processed for light microscopic evaluation or flow cytometry. CSF cytology can provide pathologic diagnoses in many oncologic cases. Immunohistochemical assays are also possible, making the cytologic analysis of CSF somewhat comparable to tissue biopsy in the range of qualitative information it can provide. However, CSF cytology has a low sensitivity (45\%), unless performed repeatedly on the same patient, making it an inaccurate and impractical brain tumor screening modality by itself ${ }^{[16,17]}$.

Arguably, modern pediatric intracranial tumor serum biomarker assay development began in the 1960s and 70 s in the field of germ cell tumor diagnostics. Research with immunoperoxidase staining of testis germ cell tumors revealed excesses in alfa-fetoprotein (AFP) and beta human chorionic gonadotropin ( $\beta$ HCG) production within the tissues of some tumor types ${ }^{[18]}$. Immunostaining and radioimmunoassay techniques quickly proliferated for these compounds; and by the mid-1970s, pathologists were able to utilize AFP, $\beta H C G$, as well as other proteins, to distinguish endodermal sinus tumors, choriocarcinomas, dysgerminomas, and teratomas on immunohistochemical review and via serum-based tests. 
In 1979, Jeffrey Allen, MD and colleagues at Memorial Sloan-Kettering applied serum and CSF AFP/BHCG radioimmunoassays for use in a group of 6 pediatric patients with biopsy proven intracranial germ cell tumors. This study was not powered to allow for statistical discrimination of the results, but it demonstrated, within individual cases, high correlations between serum AFP and CSF $\beta$ HCG levels and the presence of intracranial germ cell tumors. Furthermore, those patients with elevated AFP or $\beta H C G$ assay levels had complete normalization of their serum and CSF levels concurrent with successful tumor radiographic response to therapy ${ }^{[19]}$. This work has been expanded upon numerous times since, and the correlations found in Allen et al. ${ }^{[19]}$, s paper have proven to be robust within larger cohorts. AFP and $\beta$ HCG serum and CSF assays have now become routine components of intracranial germ cell tumor diagnostics, in some cases obviating the need for tissue sampling entirely ${ }^{[20-23]}$.

The story of AFP/BHCG serum and CSF assays is a rare success story in the realm of clinical oncologic biomarkers for pediatric brain tumor patients, and one that has, frustratingly, not been matched since. No other intracranial pediatric tumor has a widely accepted diagnostic peripheral biomarker capable - in select circumstances - of replacing tissue biopsy in the clinical evaluation algorithm ${ }^{[23]}$. Even for intracranial germ cell tumors, AFP/ $\beta$ HCG serum and CSF assays can provide false negatives, and research continues as we seek ever more reliable biofluid-based biomarkers.

\section{CSF biomarkers}

The most studied and fruitful biofluid target for pediatric oncologic biomarkers is CSF. A normally lowprotein, relatively acellular biofluid ${ }^{[24]}, \mathrm{CSF}$ is a natural choice for mining biomarker data for central nervous system (CNS) pathologies as it lies in direct contact with the whole of the CNS's pial and ependymal surfaces. Cells, both pathologic and normal, shed proteins and nucleic acids, be they naked or within extracellular vesicles, into the extracellular spaces. These compounds and vesicles will accumulate within the local biofluid compartments. In the case of the CNS, intravascular spaces, parenchymal interstitial spaces, and the intraventricular/subarachnoid spaces represent the major extracellular compartments where biomarkers can collect. With diffusion into the intravascular spaces being limited by the blood brain barrier $(\mathrm{BBB})^{[25]}$, the CSF and interstitial spaces, theoretically, should be the most rich in cytologic, genetic, and protein markers of tumor growth ${ }^{[16]}$. Most CSF based biomarker studies have focused on detecting: (1) tumor cells; (2) cellfree tumor DNA; (3) non-coding RNA; or (4) tumor-related metabolites. The authors have already discussed CSF cytology (i.e., detecting tumor cells) in the previous section, so we will only focus on the last three biomarker sources going forward.

\section{Cell-free DNA}

Circulating, cell-free tumor DNA (cfDNA) analysis employs several techniques to identify specific genetic sequences or screen for arrays of genetic sequences within biofluids. Methods for detection of genomic alterations in cfDNA are mainly PCR-based assays: real-time PCR, methylation-specific PCR, droplet digital PCR, and next-generation sequencing (NGS). The latter two techniques have particularly improved the sensitivity of cfDNA detection compared to older PCR-based assays ${ }^{[2]}$. While not specifically confined to use in the CSF, it has been most successful at correlating with brain tumor pathologies when examined in the CSF, due to the fact that non-CSF biofluids typically contain a very small percentage $(\leq 1 \%)$ of brain tumor genetic material in a sea of normal tissue genetic material ${ }^{[27]}$. Within CSF, cfDNA has been shown to detect the presence of a CNS neoplasm at rates significantly higher than CSF cytologic analysis ${ }^{[28]}$, as well as identify clinically relevant mutations, even when present at strikingly low frequencies $\left(1: 1 \times 10^{7}\right)$, through the use of NGS techniques like duplex sequencing ${ }^{[29]}$.

CSF cfDNA has been shown in several studies of adult intracranial tumor patients to exceed CSF cytologic detection levels when specific mutations are screened for (EGFR for glioblastoma, KRAS for non-small cell lung cancer, BRAF p. V600E for melanoma, etc. $)^{[27,28,30,31]}$. Among pediatric brain tumor patients, 
this biomarker has been only sparsely examined and almost exclusively in CSF. Despite cfDNA's limited utilization, to date, in pediatric brain tumor biomarker development, the authors feel that it bears special discussion, due to its potential as a low-risk diagnostic for midline gliomas.

Midline gliomas represent a one of the most difficult groups of pediatric primary brain tumors to treat. Characterized by a $\mathrm{H} 3 \mathrm{~K} 27 \mathrm{M}$ histone mutation ${ }^{[32]}$, these tumors are generally aggressive and often not safely surgically accessible ${ }^{[33]}$, making it difficult for clinicians to acquire biopsies. This limits the amount of molecular information available to direct therapy and inform prognosis, and it elevates the clinical need for a safe, reliable method of extracting molecular information from these tumor patients.

Using cfDNA isolated from CSF samples from pediatric brain tumor patients, researchers have made significant progress towards the detection of diffuse midline glioma histone mutations important for prognostication. A study conducted by Huang et al.$^{[34]}$ that reviewed CSF samples from 6 pediatric patients with diffuse midline gliomas found that the $\mathrm{H} 3 \mathrm{~F} 3 \mathrm{~A}$ mutation could be isolated or detected in up to $83 \%$ of patients, with a specificity of $100 \%$. This methodology has, subsequently, been confirmed in a larger cohort of 48 patients in a multi-institutional study. In that study by Panditharatna et al.$^{[35]}$, the authors found that the $\mathrm{H} 3 \mathrm{p}$. K27M mutations in CSF strongly correlated with the presence of a diffuse midline glioma with the same $\mathrm{H} 3 \mathrm{~K} 27 \mathrm{M}$ mutation. The amount of detectable genetic material also correlated with the response of that tumor to radiation therapy. The accuracy of the H3 p. K27M cfDNA was $87 \%$ in this study. Interestingly, Panditharatna's group also looked at the presence of the H3 p. K27M mutant genetic material in matched serum samples, as well. They reported comparable sensitivity and sensitivity results with serum as compared to CSF, though with markedly lower quantities of detectable $\mathrm{cfDNA}^{[35]}$.

CSF-based cfDNA does have important limitations that have yet to be overcome. While sensitivity for intracranial tumor detection with CSF-based cfDNA is superior to CSF cytology in general, its sensitivity for primary CNS tumors seems to be much less than for extra-CNS neoplasm. In a study of 53 adult patients with intracranial tumors, $62.5 \%$ of patients with metastatic CNS tumors had detectable tumor-specific mutant cfDNA in the CSF, while only $50 \%$ of patients with primary CNS neoplasms had detectable cfDNA in the $\mathrm{CSF}^{[27]}$. cfDNA detection in the CSF may be limited by anatomic factors, such as tumor location relative to CSF cisterns. A study of 35 pediatric and adult patients with primary brain tumors found that $86 \%$ of tumors abutting a CSF cistern had detectable cfDNA in the CSF, but none of the tumors with entirely parenchymal locations had detectable CSF $\mathrm{cfDNA}^{[36]}$. Tumor biology may also limit detection as some authors have noted low to absent rates of cfDNA detection even for some ependymomas with extensive surface contact with $\mathrm{CSF}^{[37]}$.

\section{Non-coding RNA}

Non-coding RNA, predominantly miRNA, are small (18-25 nucleotides) RNA that function to regulate mRNA pre- and post-translationally. miRNA form from a precursor RNA (pri-miRNA) that is cleaved by the RNase III nuclear enzyme Drosha into a 60-70 nucleotide intermediate known as pre-miRNA, which is then exported from the nucleus via Exportin-5. Once in the cytoplasm, pre-miRNA is cleaved again by Dicer, another RNase III enzyme, into miRNA, which then complexes with a transactivation-responsive RNA binding protein and Argonaute to form an RNA-induced silencing complex ${ }^{[38]}$. This miRNA-enzyme complex is the active unit at the end of miRNA biogenesis, and it is capable of recognizing complementary mRNA and (1) inhibiting translation initiation via cap-40S association; (2) inhibiting translation initiation via 40S-AUG-60S association; (3) inhibiting elongation; (4) causing premature ribosome drop-off; (5) causing cotranslational protein degradation; (6) causing sequestration of mRNA in P-bodies; (7) causing increased mRNA degradation; (8) increasing mRNA cleavage; or (9) effecting transcriptional inhibition by interaction with promoter sequences or increased methylation of promoters ${ }^{[39]}$.

There are currently $>1,900$ known human miRNA (miRbase.org) regulating at least $30 \%$ of human genes ${ }^{[40]}$. Table 1 lists some of the more prominent miRNA implicated in pediatric brain tumor biology ${ }^{[11-43]}$. These 
Table 1. Summary of commonly implicated miRNA alterations in pediatric brain tumors

\begin{tabular}{|c|c|c|c|c|}
\hline MiRNA & Tumor types & Regulation & Potential actions & Ref. \\
\hline MIR-15B & Glioma & Upregulated & Modulates multi-drug resistance and cell migration & {$[16,47]$} \\
\hline MIR-21 & $\begin{array}{l}\text { Glioma } \\
\text { Medulloblastoma } \\
\text { Ependymoma }\end{array}$ & $\begin{array}{l}\text { Upregulated } \\
\text { Upregulated } \\
\text { Upregulated }\end{array}$ & $\begin{array}{l}\text { Targets PTEN, PDCD4, Bcl2 and other tumor } \\
\text { suppressor genes. }\end{array}$ & {$[42,47,48]$} \\
\hline MIR-23A & Glioma & Upregulated & May regulate cell migration and apoptosis. & [44] \\
\hline MIR-34A & Ependymoma & Upregulated & Regulates apoptosis through SIRT1 & {$[42]$} \\
\hline MIR-124A & Medulloblastoma & Downregulated & Modulates glycolysis and cell cycle through CDK6 & {$[43,49]$} \\
\hline MIR-125B & $\begin{array}{l}\text { Glioma } \\
\text { Medulloblastoma }\end{array}$ & $\begin{array}{l}\text { Upregulated } \\
\text { Downregulated }\end{array}$ & SHH pathway modulation and apoptosis & {$[16,47-49]$} \\
\hline MIR-128A & Medulloblastoma & Upregulated & Tumor growth and apoptosis via MYC and $\mathrm{Bcl} 2$ & {$[43]$} \\
\hline MIR-146B & Glioma & Upregulated & Suppresses stemness and migration & [44] \\
\hline MIR-518B & $\begin{array}{l}\text { Glioma } \\
\text { Ependymoma }\end{array}$ & $\begin{array}{l}\text { Upregulated } \\
\text { Downregulated }\end{array}$ & Tumor suppressor acting through PDGFRB & {$[50]$} \\
\hline
\end{tabular}

molecules are secreted into the extracellular spaces, predominantly in microvesicles, apoptotic bodies, and exosomes. Within these vesicles, the miRNA are protected from degradation by endogenous RNases, making them an unusually stable transcript compared to other forms of RNA. Furthermore, research has shown that extracellular vesicles from tumor patients tend to be particularly enriched with tumor-related $\operatorname{miRNA}^{[44,45]}$, and these extracellular vesicles can induced oncogenic protein expression changes in adjacent, normal cells ${ }^{[46]}$.

A myriad of miRNA have been detected in the CSF of adult brain tumor patients, most prominently miR-21, miR-15b, miR-125b, and miR-22 $3^{[16,44,48,49]}$. These markers individually or in combination with other miRNA have demonstrated high levels of specificity and sensitivity for gliomas and medulloblastomas ${ }^{[47,49]}$. However, there are no published articles at the time of this review analyzing the miRNA in the CSF of pediatric glioma, embryonal, or ependymal tumor patients in isolation from adult populations. The composition and clinical applicability of miRNA in the CSF of pediatric brain tumor patients remains a significant knowledge gap, at present, in the field of pediatric neuro-oncology.

\section{Tumor metabolites and proteins}

Aberrations in tumor metabolism and cell signaling pathways relative to normal tissues tends to lead to an accumulation of well-characterized small molecules that can be used to predict the presence of a malignancy; and in certain instances, even predict the molecular signature of that malignancy ${ }^{[51]}$. Dyscrasias have been identified in all of the major metabolic cycles employed by cancer cells, including glucose metabolism, the pentose phosphate pathway, amino acid metabolism, and fatty acid metabolism, as well as many proliferative signaling pathways, such as the PI3K/AKT and WNT/ $\beta$-catenin pathways ${ }^{[8,16]}$. Lactate, isocitrate, citrate, and D-2-hydroxyglutarate are metabolites known to accumulate in gliomas utilizing aerobic glycolysis as their dominant ATP source ${ }^{[52]}$. D-2-hydroxyglutarate, in particular, has been shown to be elevated in the CSF of patients with IDH1 mutant gliomas, and its detection in the CSF may be a surrogate for this prognostically important mutation ${ }^{[53]}$.

As with CSF-based miRNA, very little research has been done examining the use of CSF metabolites to diagnose, track, and molecularly subtype pediatric brain tumors. What work has been done revolves around monoamine metabolism in pediatric brain tumors. In 1987, Bostrom and Mirkin looked at the concentrations of homovanillic acid (HVA), hydroxymethoxyphenylethyleneglycol (MHPG), and vanillylmandelic acid in the CSF of adult and pediatric patients with leukemia, glial, neuroectodermal, or retinoblastoma tumor histories. In their study, MHPG and VMA were significantly elevated among patients with primary CNS tumors or neuroblastoma cranial metastases, suggesting that these metabolites increased in response to disruption of the BBB or mass effect within the $\mathrm{CNS}^{[54]}$. This work was followed in 2014 by a study by Varela et al. ${ }^{[5]}$ of 22 pediatric patients with posterior fossa astrocytomas, medulloblastomas, 
and one case of an ependymoma. Ventricular CSF samples and serum samples were acquired and levels of MHPG, HVA, and 5-hydroxyindoleacetic acid were measured. The authors found that MHPG levels were significantly higher (19.4\%) in astrocytoma patients versus medulloblastoma patients. However, none of the measured monoamine metabolites significantly varied from age-matched controls in this small study ${ }^{[55]}$.

Like tumor metabolite CSF biomarkers, most protein biomarkers investigated in CSF are part of welldefined aberrant tumor cell signaling pathways. One of the most well studied family of proteins influencing proliferation and differentiation in pediatric brain tumors is the insulin-like growth factor (IGF) family of mitogens, binding proteins, and receptors. The IGF mitogens are primarily synthesized in the liver and circulate in conjunction with any of 7 IGF binding proteins (IGFBP) to promote CNS development, among other functions. They have been implicated in the proliferation and formation of medulloblastomas and ependymomas in in vitro and murine models ${ }^{[56,57]}$, and IGF-1 levels have been shown to correlate with an individual's propensity for developing cancer ${ }^{[58]}$.

In a study of 35 CSF samples from pediatric patients, mostly medulloblastoma patients, IGFBP-3 levels were found to be significantly elevated in the CSF of medulloblastoma patients compared to control or ependymoma patients. This finding was comparable to mRNA levels for IGFBP-3 in the tumors themselves. The study did have several limitations that tempered the confidence that could be assigned to the results. The levels of IGFBP were overall highly correlated with total CSF protein levels, as has been the case with other CSF-based protein biomarkers for brain tumors ${ }^{[59,60]}$, suggesting that IGFBP may just be an indicator of BBB disruption, rather than a specifically oncologic biomarker. The authors did attempt to normalize IGFBP-3 levels to total CSF protein levels, and the significance of the finding remained. Another issue with the study was that correlation with tumor treatment could not be assessed, as follow-up CSF samples in all patients were taken within 2 weeks of surgical resection, potentially contaminating the samples with tumor cell slough and physiologic changes related to general anesthesia and surgery ${ }^{[61]}$. Even so, this study suggests that the IGF signaling pathway may be leveraged in the future to identify and track disease in pediatric patients with medulloblastoma.

Another paper by Desiderio et al. ${ }^{[62]}$ examined changes in the CSF proteome of 14 pediatric brain tumor patients and 5 controls from the time of surgical resection and at 6 days post-surgery via top down liquid chromatography-mass spectrometry. The authors found a non-significant trend towards decreased LVV-h7 and VV-h7 hemorphins in the CSF of pediatric patients with brain tumors. In Desiderio et al. ${ }^{[62]}$ s cohort, the LVV-h7 and VV-h7 protein suppression reversed in the same patients if they underwent a gross total resection of their tumor and had no metastatic tumor burden. These findings have yet to be verified in a follow-up study, and the results included CSF samples within the window of surgical contamination ${ }^{[62]}$.

A similar whole-CSF proteome approach was utilized by Saratsis et al ${ }^{[63]}$ to search for biomarkers predictive of diffuse intrinsic pontine gliomas. In this study, 55\% of patients with diffuse intrinsic pontine gliomas demonstrated elevated levels of cyclophilin A in their CSF, while no patients with alternate supratentorial gliomas or control patients had meaningfully detectable levels of the same protein. Those patients with elevated cyclophilin A levels also showed a greater tendency towards radiographic evidence of necrosis and rapid tumor progression, suggesting that cyclophilin A may be indicative of more aggressive forms of diffuse intrinsic pontine glioma ${ }^{[63]}$.

Lastly, a study of 33 pediatric medulloblastoma patients and 25 age matched controls in a multi-centered study of prostaglandin D2 synthase (PGD2S), a highly abundant glycoprotein found in CSF, found a 6-fold reduction in $\mathrm{PGD} 2 \mathrm{~S}$ levels in medulloblastoma patients compared to controls. This was a highly significant finding $(P<0.00001)$. The authors theorized that this may be related to a host response to the tumor, as it has been described in other brain tumor patients and in some demyelinating diseases. PGD2S CSF levels 
remained suppressed after tumor patients went into remission, so it is unlikely that this protein would be useful for longitudinal screening of pediatric brain tumor patients ${ }^{[64]}$.

\section{Limitations to CSF-based biomarkers}

While relatively minimally invasive, accessing the lumbar cisterns in order to collect CSF samples is still a more difficult affair than phlebotomy, saliva collection, or urine sampling. The procedures involved in CSF sampling - lumbar puncture or ventricular puncture - require skilled, advanced practice medical personnel with knowledge of basic anatomy and sterile technique. In the case of pediatric patients, sedation is sometimes required in order to perform a lumbar puncture, and it is mandatory for ventricular access procedures. These technical difficulties currently limit the availability of patient CSF as a routine diagnostic medium and will likely frustrate attempts to use CSF-based biomarker assays for screening large populations of pediatric patients. This limits the availability of patient CSF as a routine diagnostic medium.

As has been stated earlier, CSF may also be an inappropriate source of biomarker molecules for more parenchymal based tumors, where tumor cells do not make direct contact with ependymal or pial surfaces and are, therefore, less likely to release genetic material and small molecules into CSF. In reality, 70\% of pediatric brain tumors will arise in or near the 4 th cerebral ventricle, making this potential limitation applicable to a minority of cases ${ }^{[65]}$.

In the same vein, though, the tendency of pediatric brain tumors to arise near the 4 th ventricle in the posterior fossa makes lumbar puncture more perilous for patients, as drainage of CSF from the lumbar cistern, rarely, can create a pressure gradient across the infratentorial compartment in the setting of a large mass lesion. These pressure gradients, in severe cases, can lead to brainstem and cerebellar herniation through the foramen magnum, causing significant neural injury and even death ${ }^{[66]}$. For this reason, routine lumbar punctures for the purposes of oncologic screening may not be deemed safe in many pediatric brain tumor patients.

\section{Serum biomarkers}

While CSF can be problematic to acquire, more peripheral biofluids, such as serum, urine, and saliva, can and are easily acquired from pediatric patients in ambulatory settings every day. In this sense, they are far more practical sources for pediatric brain tumor biomarker discovery than CSF; but discoveries in these media must be approached cautiously, as biomarkers in these biofluids are subject to dilution and filtration at multiple points between synthesis and their collection sites, sometimes greatly compromising the fidelity of the observed biomarker concentration ${ }^{[67-69]}$.

That being said, serum remains the most successful source of clinically relevant biomarkers in practice today. Examples of serum biomarkers in clinical use include prostate specific antigen, AFP, $\beta H C G$, alanine aminotransferase, aspartate aminotransferase, lactate dehydrogenase, and carcinoembryonic antigen ${ }^{[70,71]}$. As is the case in adult oncology, most research into pediatric brain tumor peripherally circulating biomarkers has focused on protein biomarkers, similar to those just listed, but miRNA are also beginning to show promise as potentially specific and easily measured diagnostics for detecting, diagnosing, and tracking pediatric brain tumors. Due to their relatively rapid turnover in the peripheral blood stream, DNA and RNA based biomarkers are particularly well suited for gauging tumor response to therapy ${ }^{[72]}$.

\section{Non-coding RNA}

As with CSF, serum miRNA and other forms of non-coding RNA have been targeted for potential diagnostic and screening purposes in neuro-oncology. miR-21, miR-125b, miR-128, miR-15b, and miR-182 have all been implicated in adult glioma studies of miRNA signatures within patient sera ${ }^{[73]}$. Serum miR-21 and miR-15b, in particular, have been shown to strongly predict glial tumors in adult patient populations, with combined 
A

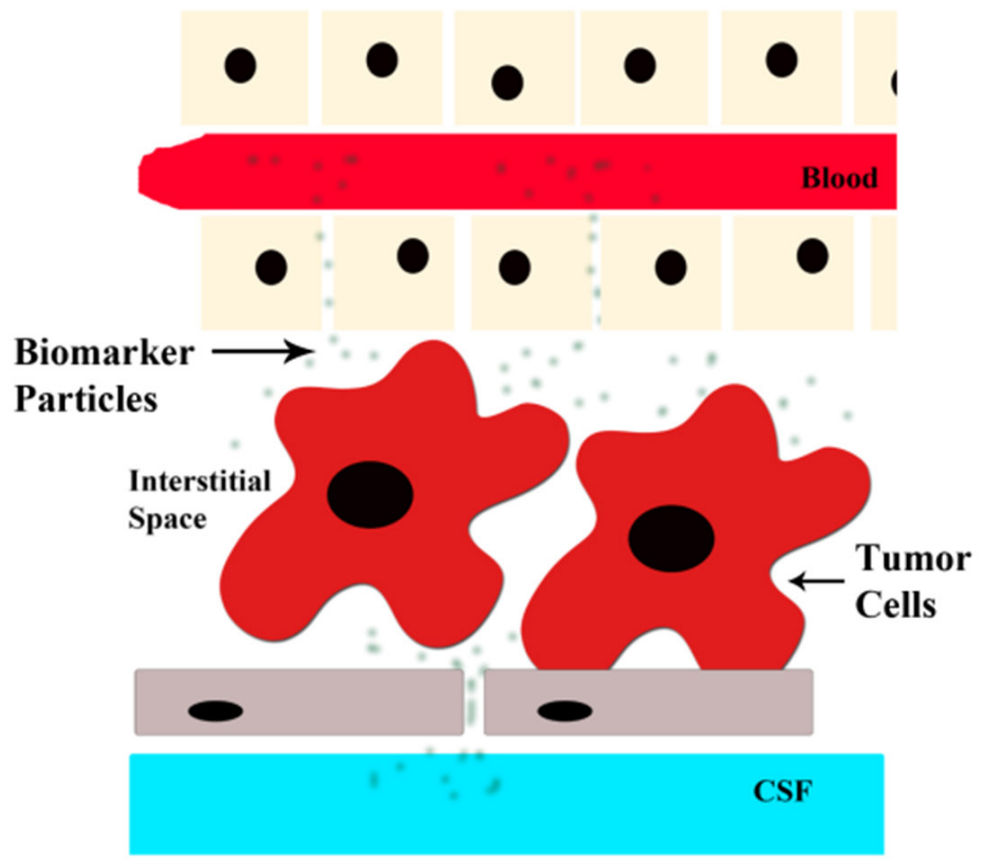

B
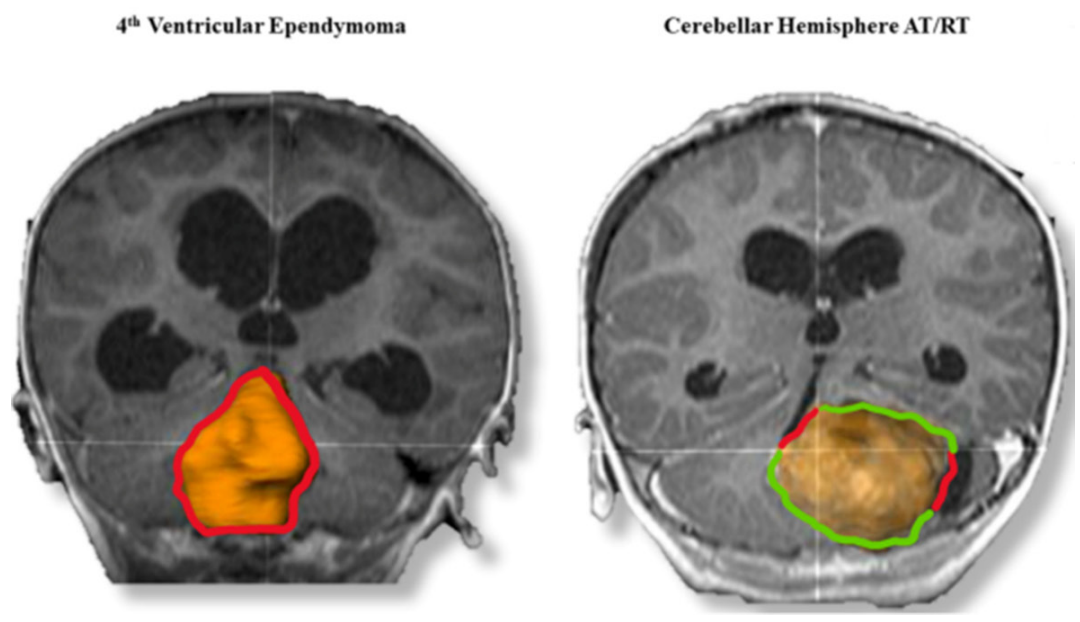

Figure 1. A: Schematic of diffusion of tumor nucleic acids, proteins, metabolites, and microvesicles into various extracellular compartments; B: Representative MRI images of an intraventricular (left) and mainly parenchymal (right) tumor with cerebrospinal fluid (CSF) contact points denoted in red and parenchymal contact points denoted in green

sensitivities and specificities of $100 \%$ in a series of 112 patients with gliomas, non-small cell lung cancer, and controls ${ }^{[74]}$. Numerous studies examining serum miRNA signatures in gastric cancer, hepatocellular carcinoma, lung cancer, and breast cancer have also demonstrated the potentially powerful predictive value of serum miRNA in screening, risk-stratifying, and tracking cancer patients ${ }^{[75-79]}$.

In the realm of pediatric neuro-oncology, however, serum miRNA have only begun to be leveraged for tumor detection and screening. The first study to examine the potential utility of serum miRNA in detecting and screening pediatric brain tumors was done by this author and their colleagues (Bookland et al. ${ }^{[4]}$ ) in a small cohort of pediatric juvenile pilocytic astrocytoma, ependymoma, and control patients. The authors identified four miRNA (miR-21, miR-15b, miR-23a, and miR-146b) that accurately predicted the presence, tumor nodule size, and response to therapy of juvenile pilocytic astrocytoma patients with a sensitivity of 
$86 \%$ and specificity of $100 \%$. In particular, levels of miR-15b, miR-21, and miR-23a correlated strongly with tumor nodule volume (miR-15b, $R^{2}=0.86 ; m i R-21 R^{2}=0.92 ; m i R-23 a, R^{2}=0.86$ ) and returned to normal levels within $24 \mathrm{~h}$ of gross total tumor resection. Interestingly, patients with tumors situated more deeply within the brain parenchyma demonstrated higher ratios of miRNA to tumor nodule volume than those more peripherally situated ${ }^{[41]}$. These results further support the notion that oncologic miRNA serum levels may be affected by tumor anatomic location, just has been speculated with CSF biomarkers [Figure 1].

This pilot study evaluating the potential utility of serum miRNA as a biomarker for pediatric brain tumors is encouraging, but this initial work also highlighted significant barriers to serum miRNA development, including: (1) normalization of miRNA profiles; (2) low miRNA yields compared to tissue or CSF sources; (3) and a poor understanding of relative contributions tumor and host tissues make to the final serum miRNA signatures ${ }^{[41,71]}$. One significant example of these challenges can be demonstrated in observing the effect that general anesthesia has on select serum miRNA levels. miR-125b, which has been implicated as an oncomir in gliomas and medulloblastomas ${ }^{[80,81]}$, is suppressed in humans and rodents after exposure to general anesthetic agents ${ }^{[41,82]}$. Yet, few miRNA biomarker studies have controlled for the effects of anesthesia miRNA levels. Indeed, controlling for anesthesia in pediatric clinical trials is an ethically and technically complicated matter that adds a layer of complexity to serum miRNA interpretation of which clinical researchers must be cognizant. This example highlights the importance of developing a thorough understanding of the interplay between oncologically-relevant miRNA and the normal functions they regulate so that confounding host and external forces acting on miRNA of interest can be controlled.

\section{Protein/small molecule}

As mentioned previously, protein and small molecule serum biomarkers have been extensively studied, and they represent, perhaps, the most significant cohort of potential biomarkers for pediatric brain tumors. An exhaustive list of all proteins and small molecules implicated in pediatric brain tumor diagnostics and prognostics is beyond the scope of this brief review, but we will touch on some of the more widely reported biomarkers in the literature.

Osteopontin is an extracellular matrix protein expressed in a wide variety of tissues and involved in mineralization, immune modulation, cell migration, and anti-apoptosis ${ }^{[83]}$. It has been shown to be overexpressed in atypical teratoid/rhabdoid tumors (AT/RT), as well as several other CNS tumors. In a series of 39 pediatric patients with AT/RT, medulloblastoma, epilepsy, or hydrocephalus, serum and CSF levels of osteopontin were shown to be significantly elevated in AT/RT patients versus medulloblastoma patients ( 2:1 in serum) and versus control patients ( 4:1 in serum). Serum osteopontin levels also correlated with AT/ RT response to therapy, and higher serum levels were associated with a more malignant disease course ${ }^{[84]}$. This work raises the possibility that osteopontin may be a highly specific and reliable biomarker for riskstratifying AT/RT patients and gauging their response to therapy.

Another protein involved in a variety of carcinogenic signaling pathways, including proliferation, immunomodulation, migration, anti-apoptosis, and chemotherapy resistance, is metallothionein. Different isomers of metallothionein have been implicated in vitro in inducing chemoresistance in neuroblastoma, melanoma, rhabdomyosarcoma, and medulloblastoma cell lines ${ }^{[85-87]}$. A group of researchers, using differential pulse voltammetry to measure serum metallothionein levels, attempted to exploit metallothionein's association with oncogenesis to see if it could be reliably detected at supernormal levels in pediatric solid tumor patients, including in 10 medulloblastoma patients and 4 ependymoma patients. All 38 pediatric solid tumor patients in this study had serum levels of metallothionein roughly $6-8$-fold higher than adult controls $(P<0.05)^{[88]}$. This work strongly suggests that serum metallothionein may be useful as a non-specific oncologic biomarker in pediatric patients, though additional work is needed to confirm the results with age-matched controls. 
A larger study of 106 pediatric patients with brain tumors, including gliomas, medulloblastomas, and ependymomas, studied the relationship between serum levels of the pro-angiogenic growth factors and pediatric brain tumors. In this study, serum vascular endothelial growth factor (VEGF) and basic fibroblast growth factor (bFGF) levels were measured at presentation and following surgical resection or debulking of the tumor. While the authors of the study found no statistically significant changes in bFGF levels between groups, serum VEGF was $16.4 \%$ higher $(P=0.05)$ in pediatric brain tumor patients compared to controls. Interestingly, subset analysis of only the glioma patients showed that serum VEGF levels were $16.4 \%$ lower $(P<0.05)$ than controls ${ }^{[89]}$. This is a curious result given glioblastoma and other high-grade glial tumors are known to overexpress VEGF ${ }^{[90]}$. The authors also found no statistically significant difference in serum VEGF or bFGF levels in any of the post-surgical patients, regardless of the degree of tumor resection achieved ${ }^{[89]}$. These results are, in the end, difficult to reconcile; and this may reflect the extremely diverse collection of pediatric brain tumors included.

Behrends et al..$^{[91]}$ in a study of 40 pediatric cancer patients, including 10 brain tumor patients, employed a less conventional method to identify humoral targets for biomarker development. In contrast to other biomarker development projects that rely on a priori knowledge of cell signaling proteins known to be abnormal in the disease process of interest, Behrend's group used SEREX technology to identify potential humoral targets, in some cases finding cancer antigens with no described function. The group utilized autologous sera and serially screened these sera against autologous cDNA expression libraries in 4 pediatric medulloblastoma patients. From this, the group identified 15 antigens. Humoral responses to these 15 antigens were then tested in the 40 pediatric cancer patients, as well as in 40 pediatric controls. Antibodies were found to 5 of the 15 antigens exclusively in pediatric cancer patients. The authors noted, though, that the humoral responses to these antigens was not uniform. Only 2-3 out of 5 medulloblastomas had detectable antibodies to any one antigen, and the humoral responses varied over time depending on response of the tumor to therapy. The authors also point out that humoral responses may change, as well, due to mutations in some tumors that support immune evasion ${ }^{[9]}$. Taken in balance, SEREX screening for humoral biomarker targets is an innovative technique for identifying novel pediatric brain tumor biomarkers, but clinical application is likely to be limited by the marked variability in humoral response across patients.

\section{Limitations to serum biomarkers in pediatric brain tumor patients}

While familiar and easily accessible, serum sources for biomarkers do have significant drawbacks. As a peripheral biofluid, the milieu of serum proteins and genetic material is affected by every organ system in the human body. Even large amounts of oncologic biomarkers can easily be diluted out by normal serum components $^{[35]}$. Additionally, it is difficult to know what sources - host or tumor - are driving the targeted biomarker concentration levels. Studies have shown that even epigenetic factors, such as a change in diet, can significantly alter measured levels of some serum biomarkers for adult cancers ${ }^{[38]}$. As with CSF, the location and biology of pediatric brain tumors also seems to play a part in serum levels of some presumptive biomarkers, with certain tumor-related proteins being undetectable outside of the $\mathrm{BBB}^{[61,63]}$.

\section{Urine}

Urine is a filtrate of serum via the glomeruli, and it represents a particularly easy and well-studied biofluid to obtain from children. Excreted oncologic biomarkers such as metanephrine and VMA have been employed clinically for decades as routine components in the work-up of several catecholamine producing solid tumors, including pheochromocytomas and neuroblastomas in both children and adults ${ }^{[92]}$.

A paper by Pricola Fehnel et al ${ }^{[93]}$ in 2016 examined the use of urinary bFGF, MMP13 and TIMP3 levels as biomarkers for juvenile pilocytic astrocytomas. The study followed 21 astroctyoma, 17 medulloblastoma, and 21 control pediatric patients with serial urine samples pre-tumor treatment and post-tumor treatment. The authors also examined bFGF and TIMP3 levels in primary juvenile pilocytic astrocytoma cell line conditioned media. They found a significant elevation in bFGF and TIMP3 urine concentrations among the 
astrocytoma patients, with a combined sensitivity and specificity of $100 \%$ and $95 \%$, respectively. Conditioned media from cultured primary astrocytoma cells also showed relative enrichment of bFGF and TIMP3, concordant with the findings in patient urine samples. Among 9 patient samples where pre- and posttreatment imaging was available, bFGF and TIMP3 levels also significantly correlated with tumor volume changes on imaging ${ }^{[93]}$.

Another, earlier project from the same group looked at VEGF, MMP2, and MMP9 in urine and CSF samples from a cohort of 28 brain tumor patients $(n=11$ pediatric, $n=17$ adult) and 23 control patients. Urinary concentrations of VEGF, MMP2 and MMP9 were all significantly increased within the tumor patient cohort; and urinary VEGF and MMP2, in particular, had excellent sensitivity and specificities for the presence of a brain tumor. VEGF had $95.2 \%$ sensitivity and $89.5 \%$ specificity, while MMP2 demonstrated $82.1 \%$ sensitivity and $95.7 \%$ specificity. Both of these proteins were undetectable in the urine of 5 patients for whom follow-up imaging demonstrated complete resolution of their tumors ${ }^{[94]}$.

Both of these studies are very encouraging for the prospect of developing a clinically deployable and accurate laboratory assay for pediatric brain tumors. However, as with all biomarker sources, urine has special limitations as a diagnostic media that have still not completely been addressed in either of the aforementioned studies. Nolen et al. ${ }^{[69]}$ laid out in an extensive analysis of over 200 potential urinary biomarkers the effects of normalization methods, population variability, and temporal variability on measured biomarker concentrations. The authors of this study found that, while urine total protein had the smallest impact on biomarker variability, none of the normalization methods tested (urine creatinine, urine albumin, urine $\mathrm{B} 2 \mathrm{M}$ ) was clearly superior to the other. Additionally, the authors observed significant intra- and inter-day variability in urine biomarker concentrations; in most cases, the coefficients of variation exceeded $50 \%{ }^{[69]}$. These findings should prompt caution when interpreting urinary biomarker data, as robust differences in biomarker concentrations between diseased and normal states will be needed to consistently overcome such high levels of biomarker variability. Even so, the work by Pricola Fehnel et al. ${ }^{[93]}$ suggests that such high levels discrimination may indeed exist for some pediatric brain tumor urinary biomarkers.

\section{Challenges of developing biomarkers from pediatric populations}

Compared to the adult neuro-oncology world, the development of circulating biomarker candidates for pediatric brain tumor patients is still in its infancy. This is partially due to a significant statistical barrier to research within pediatric brain tumor patient populations. There are an estimated 4,600 new pediatric brain tumor diagnoses each year in the United States of America ${ }^{[1]}$. This compares to an average of 22,172 new adult primary brain tumor diagnoses per year ${ }^{[95]}$. As these statistics demonstrate, pediatric brain tumor cases are relatively rare, and individual institutions often do not have enough volume to organize large scale studies on their own. Multi-centered trials and novel screening assays are needed in order to create study populations with enough power to generate meaningful conclusions.

Another issue is the lack of comparative data across biofluids and pediatric brain tumor clinical stages for individual biomarker candidates. As mentioned in this review article, there exist significant theoretical and practical limitations to each biofluid currently targeted for biomarker discovery. Additionally, there is mounting evidence that tumor stage and location relative to the biofluid of interest can alter biomarker yields ${ }^{[36,41,96]}$. A large study examining one or more biomarkers in multiple biofluids serially across early and late stages of brain tumor therapy will be needed to answer the question of which biofluid is most suitable for diagnosing and screening which pediatric brain tumors. This is a daunting ask given the difficulties researchers face accruing and maintaining large population pediatric brain tumor studies. A study by Pages et al. ${ }^{[97]}$ is currently underway examining the cfDNA in the CSF, serum, and urine of 192 pediatric brain tumor patients, but results are not available as of the production of this manuscript. It is hoped that this study and others to come like it may help to define the effect of biofluid choice on biomarker sensitivity and specificity for pediatric brain tumors. 
Table 2. Summary of select works identifying circulating biomarkers for pediatric brain tumors

\begin{tabular}{|c|c|c|c|c|c|}
\hline Source & Marker(s) & Method & Tumor type & Finding & Ref. \\
\hline CSF & $\begin{array}{l}\text { Type } 1 \text { collagen } \\
\text { IGFBP4 } \\
\text { Procollagen C-endopeptidase } \\
\text { enhance } 1 \\
\text { Glial cell-line derived neurotrophic } \\
\text { factor receptor } \alpha 2 \\
\text { Inter-alpha-trypsin inhibitor heavy } \\
\text { chain } 4 \\
\text { Neural proliferation and } \\
\text { differentiation control protein-1 }\end{array}$ & LC-MS/MS, RPPA, ELISA & Mixed Brain Tumors & $\begin{array}{l}\text { Protein signatures may discriminate } \\
\text { metastatic tumors from controls }\end{array}$ & {$[98]$} \\
\hline CSF & H3F3A /HISTIH313 mutations & $\begin{array}{l}\text { Sanger sequencing } \\
\text { (DNA isolation, nested } \\
\text { PCR) of cfDNA }\end{array}$ & $\begin{array}{l}\text { Diffuse midline } \\
\text { glioma }\end{array}$ & $\begin{array}{l}\text { Feasibility and specificity of } \\
\text { H3K } 27 M \text { detection in DNA from } \\
\text { CSF }\end{array}$ & {$[34]$} \\
\hline CSF & Prostaglandin D2 synthase & $\begin{array}{l}\text { Proteomics } \\
\text { MALDI-TOF/ELISA }\end{array}$ & Medulloblastoma & PGD2S $\downarrow$ & {$[64]$} \\
\hline CSF & Apolipoprotein A-II & $\begin{array}{l}\text { SELDI-TOF mass } \\
\text { spectrometry }\end{array}$ & Brain tumor & ApoAll level $\uparrow$ & {$[59]$} \\
\hline CSF & $\begin{array}{l}\text { LVV } \\
\text { VV-hemorphin-7 }\end{array}$ & Proteomics LC-MS & Mixed Brain Tumors & LVV-ハVV-h7 $\downarrow$ in tumor patients & {$[62]$} \\
\hline CSF & c-Tau & ELISA & $\begin{array}{l}\text { Medulloblastoma } \\
\text { Ependymoma } \\
\text { Astrocytoma }\end{array}$ & c-Tau $\uparrow$ & {$[99]$} \\
\hline CSF & CyclophillinA Dimethyarginase 1 & $\begin{array}{l}\text { Proteomics, mass } \\
\text { spectrometry }\end{array}$ & DIPG & $\uparrow c C y p A$ and DDAH1 & {$[63]$} \\
\hline CSF & cfDNA & $\begin{array}{l}\text { Genome-wide } \\
\text { sequencing }\end{array}$ & $\begin{array}{l}\text { High Grade Glioma } \\
\text { JPA } \\
\text { Medulloblastoma } \\
\text { Ependymoma }\end{array}$ & $\begin{array}{l}\text { cfDNA detected in } 74 \% \text { of tumor } \\
\text { patient CSF }\end{array}$ & {$[36]$} \\
\hline CSF, serum & Human chorionic gonadotropin & Enzyme immunoassay & Germinoma & $\begin{array}{l}\text { HCG } \uparrow \text { in patients with recurrence } \\
\text { events }\end{array}$ & {$[22]$} \\
\hline CSF, plasma & IGF, IGFBPs, IGFRs & Microarray, RIA, western & $\begin{array}{l}\text { Ependymoma } \\
\text { Medulloblastoma }\end{array}$ & IGFBP-2/IGFBP-3 $\uparrow$ tumor patients & {$[61]$} \\
\hline CSF, plasma & Osteopontin & ELISA, qPCR & $\begin{array}{l}\text { Medullbolastoma } \\
\text { AT/RT }\end{array}$ & Osteopontin $\uparrow$ in AT/RT recurrence & {$[84]$} \\
\hline CSF, serum & $\begin{array}{l}\text { AFP } \\
\text { beta-hCG }\end{array}$ & Immunoenzyme & Germinoma NGGCT & $\begin{array}{l}\uparrow A F P \text { in serum } \\
\uparrow \mathrm{bHCG} \text { in } \mathrm{CSF}\end{array}$ & {$[20]$} \\
\hline CSF, serum & $\begin{array}{l}\text { miR-371a-3p } \\
\text { miR-372-3p } \\
\text { miR-373-3p } \\
\text { miR-367-3p }\end{array}$ & qRT-PCR & Germ cell tumors & $\operatorname{miRNA} \uparrow$ & {$[100]$} \\
\hline CSF, plasma & H3K27M-mutant cfDNA & Digital drople PCR & $\begin{array}{l}\text { Diffuse midline } \\
\text { glioma }\end{array}$ & $\begin{array}{l}\mathrm{H} 3 \mathrm{~K} 27 \mathrm{M} \text { mutant cfDNA correlates } \\
\text { with treatment response }\end{array}$ & [35] \\
\hline Blood/serum & ERCC2 methylation & Illumina Beadchip & Medulloblastoma & $\begin{array}{l}\text { ERCC2 promoter methylation } \uparrow \\
\text { correlates with poor prognosis }\end{array}$ & [101] \\
\hline Serum & Metallothionein & $\begin{array}{l}\text { Differential pulse } \\
\text { voltametry }\end{array}$ & $\begin{array}{l}\text { Medulloblastoma } \\
\text { Ependymoma }\end{array}$ & $\uparrow$ in cancer patient's serum & {$[88]$} \\
\hline Blood/serum & miRNA profile & $\mathrm{qPCR}$ & JPA & $\begin{array}{l}\uparrow \operatorname{miR} 21 \text {, mir15b, } \\
\text { miR23, miR146b correlated with } \\
\text { tumor mural nodule size }\end{array}$ & [41] \\
\hline Serum & $\begin{array}{l}\text { VEGF } \\
\text { bFGF }\end{array}$ & ELISA & High grade glioma & VEGF $\uparrow$ & [89] \\
\hline Urine, CSF & $\begin{array}{l}\text { MMP-2 } \\
\text { MMP-9 } \\
\text { MMP-NGAL } \\
\text { VEGF }\end{array}$ & ELISA & JPA & $\begin{array}{l}\text { MMP-2, MMP-9, MMP-NGAL, } \\
\text { VEGF levels } \uparrow\end{array}$ & {$[94]$} \\
\hline Urine & $\begin{array}{l}\text { bFGF } \\
\text { TIMP3 } \\
\text { MMP-13 }\end{array}$ & ELISA & JPA & $\begin{array}{l}\text { bFGF, TIMP3 } \uparrow \\
\text { MMP-13 } \downarrow\end{array}$ & {$[93]$} \\
\hline Urine & Netrin-1 & ELISA & Medulloblastoma & $\begin{array}{l}\text { Netrin- } 1 \uparrow \text { in metastatic } \\
\text { medulloblastoma }\end{array}$ & {$[102]$} \\
\hline
\end{tabular}

CSF: cerebrospinal fluid; cfDNA: cell-free tumor DNA; IGF: insulin-like growth factor; IGFBPs: IGF binding proteins; VEGF: vascular endothelial growth factor; bFGF: basic fibroblast growth factor 


\section{CONCLUSION}

Pediatric brain tumors remain the most significant oncologic cause of death among children, and pediatric brain tumor diagnosis and longitudinal screening is heavily reliant on MRI - a very limited and expensive screening tool. The creation of reliable and easily deployed biomarker-based assays could dramatically improve pediatric brain tumor detection. Early detection could, in turn, improve current care by allowing for early surgery. Patient therapy could also be tailored based on biomarker-directed tumor risk stratification.

While there are currently many circulating biomarker candidates in CSF, serum, and urine, all the studies to date are hobbled by small cohort size and often mixed populations of tumor types [Table 2]. Follow-up multi-centered studies have failed to materialize for most biomarkers, leaving the validity of virtually all of these candidate pediatric brain tumor biomarkers in doubt. Hopefully, with continued interest, time, and collaboration, these current research needs will be met.

\section{DECLARATIONS}

\section{Authors' contributions}

Made substantial contributions to conception and design of the review and performed data collection: Bookland MJ

Performed data acquisition, as well as provided administrative, technical, and material support: Kolmakova A

\section{Availability of data and materials}

Not applicable.

\section{Financial support and sponsorship}

None.

\section{Conflicts of interest}

All authors declared that there are no conflicts of interest.

\section{Ethical approval and consent to participate}

Not applicable.

\section{Consent for publication}

Not applicable.

\section{Copyright}

(c) The Author(s) 2019.

\section{REFERENCES}

1. Withrow DR, de Gonzalez AB, Lam CJK, Warren KE, Shiels MS. Trends in pediatric central nervous system tumor incidence in the United States, 1998-2013. Cancer Epidemiol Biomarkers Prev 2019;28:522-30.

2. Siegel RL, Miller KD, Jemal A. Cancer statistics, 2018. CA Cancer J Clin 2018;68:7-30.

3. Ward E, DeSantis C, Robbins A, Kohler B, Jemal A. Childhood and adolescent cancer statistics, 2014. CA Cancer J Clin 2014;64:83-103.

4. Khatua S, Ramaswamy V, Bouffet E. Current therapy and the evolving molecular landscape of paediatric ependymoma. Eur J Cancer 2017;70:34-41.

5. Qaddoumi I, Sultan I, Gajjar A. Outcome and prognostic features in pediatric gliomas: a review of 6212 cases from the surveillance, epidemiology, and end results database. Cancer 2009;115:5761-70.

6. Bornhorst M, Frappaz D, Packer RJ. Pilocytic astrocytomas. Handb Clin Neurol 2016;134:329-44.

7. Ramaswamy V, Remke M, Adamski J, Bartels U, Tabori U, et al. Medulloblastoma subgroup-specific outcomes in irradiated children: who are the true high-risk patients? Neuro Oncol 2016;18:291-7. 
8. Taylor MD, Northcott PA, Korshunov A, Remke M, Cho YJ, et al. Molecular subgroups of medulloblastoma: the current consensus. Acta Neuropathol 2012;123:465-72.

9. Dörner L, Fritsch MJ, Stark AM, Mehdorn HM. Posterior fossa tumors in children: how long does it take to establish the diagnosis? Childs Nerv Syst 2007;23:887-90.

10. Andropoulos DB, Greene MF. Anesthesia and developing brains - implications of the FDA warning. N Engl J Med 2017;376:905-7.

11. Sheppard JP, Nguyen T, Alkhalid Y, Beckett JS, Salamon N, et al. Risk of brain tumor induction from pediatric head CT procedures: a systematic literature review. Brain Tumor Res Treat 2018;6:1-7.

12. Bjur KA, Payne ET, Nemergut ME, Hu D, Flick RP. Anesthetic-related neurotoxicity and neuroimaging inchildren: a call for conversation. J Child Neurol 2017;32:594-602.

13. Tomita T, McLone DG. Spontaneous seeding of medulloblastoma: results of cerebrospinal fluid cytology and arachnoid biopsy from the cisterna magna. Neurosurgery 1983;12:265-7.

14. Al-Abbadi MA. Basics of cytology. Avicenna J Med 2011;1:18-28.

15. Gajjar A, Fouladi M, Walter AW, Thompson SJ, Reardon DA, et al. Comparison of lumbar and shunt cerebrospinal fluid specimens for cytologic detection of leptomeningeal disease in pediatric patients with brain tumors. J Clin Oncol 1999;17:1825-8.

16. Zorofchian S, Iqbal F, Rao M, Aung PP, Esquenazi Y, et al. Circulating tumour DNA, microRNA and metabolites in cerebrospinal fluid as biomarkers for central nervous system malignancies. J Clin Pathol 2019;72:271-280.

17. Shalaby T, Achini F, Grotzer MA. Targeting cerebrospinal fluid for discovery of brain cancer biomarkers. J Cancer Metastasis Treat 2016;2:176-87.

18. Kurman RJ, Scardino PT, McIntire KR, Waldmann TA, Javadpour N. Cellular localization of alpha-fetoprotein and human chorionic gonadotropin in germ cell tumors of the testis using and indirect immunoperoxidase technique. Cancer 1977;40:2136-51.

19. Allen JC, Nisselbaum J, Epstein F, Rosen G, Schwartz MK. Alphafetoprotein and human chorionic gonadotropin determination in cerebrospinal fluid. An aid to the diagnosis and management of intracranial germ-cell tumors. J Neurosurg 1979;51:368-74.

20. Qaddoumi I, Sane M, Li S, Kocak M, Pai-Panandiker A, et al. Diagnostic utility and correlation of tumor markers in the serum and cerebrospinal fluid of children with intracranial germ cell tumors. Childs Nerv Syst 2012;28:1017-24.

21. Seregni E, Massimino M, Nerini Molteni S, Pallotti F, van der Hiel B, et al. Serum and cerebrospinal fluid human chorionic gonadotropin (hCG) and alpha-fetoprotein (AFP) in intracranial germ cell tumors. Int J Biol Markers 2002;17:112-8.

22. Fukuoka K, Yanagisawa T, Suzuki T, Shirahata M, Adachi JI, et al. Human chorionic gonadotropin detection in cerebrospinal fluid of patients with a germinoma and its prognostic significance: assessment by using a highly sensitive enzyme immunoassay. J Neurosurg Pediatr 2016;18:573-7.

23. Allen J, Chacko J, Donahue B, Dhall G, Kretschmar C, et al. Diagnostic sensitivity of serum and lumbar CSF bHCG in newly diagnosed CNS germinoma. Pediatr Blood Cancer 2012;59:1180-2.

24. Seehusen DA, Reeves MM, Fomin DA. Cerebrospinal fluid analysis. Am Fam Physician 2003;68:1103-8.

25. Daneman R. The blood-brain barrier in health and disease. Ann Neurol 2012;72:648-72.

26. Peng M, Chen C, Hulbert A, Brock MV, Yu F. Non-blood circulating tumor DNA detection in cancer. Oncotarget 2017;8:69162-73.

27. Pentsova EI, Shah RH, Tang J, Boire A, You D, et al. Evaluating cancer of the central nervous system through next-generation sequencing of cerebrospinal fluid. J Clin Oncol 2016;34:2404-15.

28. Ballester LY, Glitza Oliva IC, Douse DY, Chen MM, Lan C, et al. Evaluating circulating tumor DNA from the cerebrospinal fluid of patients with melanoma and leptomeningeal disease. J Neuropathol Exp Neurol 2018;77:628-35.

29. Kennedy SR, Schmitt MW, Fox EJ, Kohrn BF, Salk JJ, et al. Detecting ultralow-frequency mutations by duplex sequencing. Nat Protoc 2014;9:2586-606.

30. Li Y, Pan W, Connolly ID, Reddy S, Nagpal S, et al. Tumor DNA in cerebral spinal fluid reflects clinical course in a patient with melanoma leptomeningeal brain metastases. J Neurooncol 2016;128:93-100.

31. Swinkels DW, de Kok JB, Hanselaar A, Lamers K, Boerman RH. Early detection of leptomeningeal metastasis by PCR examination of tumor-derived K-ras DNA in cerebrospinal fluid. Clin Chem 2000;46:132-3.

32. Wu G, Broniscer A, McEachron TA, Lu C, Paugh BS, et al. Somatic histone H3 alterations in pediatric diffuse intrinsic pontine gliomas and non-brainstem glioblastomas. Nat Genet 2012;44:251-3.

33. Wolff JE, Rytting ME, Vats TS, Zage PE, Ater JL, et al. Treatment of recurrent diffuse intrinsic pontine glioma: the MD anderson cancer center experience. J Neurooncol 2012;106:391-7.

34. Huang TY, Piunti A, Lulla RR, Qi J, Horbinski CM, et al. Detection of histone H3 mutations in cerebrospinal fluid-derived tumor DNA from children with diffuse midline glioma. Acta Neuropathol Commun 2017;5:28.

35. Panditharatna E, Kilburn LB, Aboian MS, Kambhampati M, Gordish-Dressman H, et al. Clinically relevant and minimally invasive tumor surveillance of pediatric diffuse midline gliomas using patient-derived liquid biopsy. Clin Cancer Res 2018;24:5850-9.

36. Wang Y, Springer S, Zhang M, McMahon KW, Kinde I, et al. Detection of tumor-derived DNA in cerebrospinal fluid of patients with primary tumors of the brain and spinal cord. Proc Natl Acad Sci U S A 2015;112:9704-9.

37. Connolly ID, Li Y, Pan W, Johnson E, You L, et al. A pilot study on the use of cerebrospinal fluid cell-free DNA in intramedullary spinal ependymoma. J Neurooncol 2017;135:29-36.

38. Kala R, Peek GW, Hardy TM, Tollefsbol TO. MicroRNAs: an emerging science in cancer epigenetics. J Clin Bioinforma 2013;3:6.

39. Morozova N, Zinovyev A, Nonne N, Pritchard LL, Gorban AN, et al. Kinetic signatures of microRNA modes of action. RNA 2012;18:1635-55.

40. Lewis BP, Burge CB, Bartel DP. Conserved seed pairing, often flanked by adenosines, indicates that thousands of human genes are microRNA targets. Cell 2005;120:15-20.

41. Bookland M, Tang-Schomer M, Gillan E, Kolmakova A. Circulating serum oncologic miRNA in pediatric juvenile pilocytic astrocytoma patients predicts mural nodule volume. Acta Neurochir (Wien) 2018;160:1571-81. 
42. Costa FF, Bischof JM, Vanin EF, Lulla RR, Wang M, et al. Identification of microRNAs as potential prognostic markers in ependymoma. PLoS One 2011;6:e25114.

43. Vidal DO, Marques MM, Lopes LF, Reis RM. The role of microRNAs in medulloblastoma. Pediatr Hematol Oncol 2013;30:367-78.

44. Akers JC, Ramakrishnan V, Kim R, Phillips S, Kaimal V, et al. miRNA contents of cerebrospinal fluid extracellular vesicles in glioblastoma patients. J Neurooncol 2015;123:205-16.

45. Skog J, Würdinger T, van Rijn S, Meijer DH, Gainche L, et al. Glioblastoma microvesicles transport RNA and proteins that promote tumour growth and provide diagnostic biomarkers. Nat Cell Biol 2008;10:1470-6.

46. Tüzesi Á, Kling T, Wenger A, Lunavat TR, Jang SC, et al. Pediatric brain tumor cells release exosomes with a miRNA repertoire that differs from exosomes secreted by normal cells. Oncotarget 2017;8:90164-75.

47. Baraniskin A, Kuhnhenn J, Schlegel U, Maghnouj A, Zöllner H, et al. Identification of microRNAs in the cerebrospinal fluid as biomarker for the diagnosis of glioma. Neuro Oncol 2012;14:29-33.

48. Shi R, Wang PY, Li XY, Chen JX, Li Y, et al. Exosomal levels of miRNA-21 from cerebrospinal fluids associated with poor prognosis and tumor recurrence of glioma patients. Oncotarget 2015;6:26971-81.

49. Drusco A, Bottoni A, Laganà $\mathrm{A}$, Acunzo $\mathrm{M}$, Fassan $\mathrm{M}$, et al. A differentially expressed set of microRNAs in cerebro-spinal fluid (CSF) can diagnose CNS malignancies. Oncotarget 2015;6:20829-39.

50. Xu X, Zhang F, Chen X, Ying Q. MicroRNA-518b functions as a tumor suppressor in glioblastoma by targeting PDGFRB. Mol Med Rep 2017:16:5326-32.

51. Blüml S, Margol AS, Sposto R, Kennedy RJ, Robison NJ, et al. Molecular subgroups of medulloblastoma identification using noninvasive magnetic resonance spectroscopy. Neuro Oncol 2016;18:126-31.

52. Nakamizo S, Sasayama T, Shinohara M, Irino Y, Nishiumi S, et al. GC/MS-based metabolomic analysis of cerebrospinal fluid (CSF) from glioma patients. J Neurooncol 2013;113:65-74.

53. Kalinina J, Ahn J, Devi NS, Wang L, Li Y, et al. Selective detection of the D-enantiomer of 2-Hydroxyglutarate in the CSF of glioma patients with mutated isocitrate dehydrogenase. Clin Cancer Res 2016;22:6256-65.

54. Bostrom B, Mirkin BL. Elevation of cerebrospinal fluid catecholamine metabolites in patients with intracranial tumors of neuroectodermal origin. J Clin Oncol 1987;5:1090-7.

55. Varela M, Alexiou GA, Liakopoulou M, Papakonstantinou E, Pitsouni D, et al. Monoamine metabolites in ventricular CSF of children with posterior fossa tumors: correlation with tumor histology and cognitive functioning. J Neurosurg Pediatr 2014;13:375-9.

56. Del Valle L, Enam S, Lassak A, Wang JY, Croul S, et al. Insulin-like growth factor I receptor activity in human medulloblastomas. Clin Cancer Res 2002;8:1822-30.

57. Zumkeller W, Westphal M. The IGF/IGFBP system in CNS malignancy. Mol Pathol 2001;54:227-9.

58. Gallagher EJ, LeRoith D. Is growth hormone resistance/IGF-1 reduction good for you? Cell Metab 2011;13:355-6.

59. de Bont JM, den Boer ML, Reddingius RE, Jansen J, Passier M, et al. Identification of apolipoprotein A-II in cerebrospinal fluid of pediatric brain tumor patients by protein expression profiling. Clin Chem 2006;52:1501-9.

60. de Bont JM, Vanderstichele H, Reddingius RE, Pieters R, van Gool SW. Increased total-Tau levels in cerebrospinal fluid of pediatric hydrocephalus and brain tumor patients. Eur J Paediatr Neurol 2008;12:334-41.

61. de Bont JM, van Doorn J, Reddingius RE, Graat GH, Passier MM, et al. Various components of the insulin-like growth factor system in tumor tissue, cerebrospinal fluid and peripheral blood of pediatric medulloblastoma and ependymoma patients. Int J Cancer 2008;123:594-600.

62. Desiderio C, D'Angelo L, Rossetti DV, Iavarone F, Giardina B, et al. Cerebrospinal fluid top-down proteomics evidenced the potential biomarker role of LVV- and VV-hemorphin-7 in posterior cranial fossa pediatric brain tumors. Proteomics 2012;12:2158-66.

63. Saratsis AM, Yadavilli S, Magge S, Rood BR, Perez J, et al. Insights into pediatric diffuse intrinsic pontine glioma through proteomic analysis of cerebrospinal fluid. Neuro Oncol 2012;14:547-60.

64. Rajagopal MU, Hathout Y, MacDonald TJ, Kieran MW, Gururangan S, et al. Proteomic profiling of cerebrospinal fluid identifies prostaglandin D2 synthase as a putative biomarker for pediatric medulloblastoma: a pediatric brain tumor consortium study. Proteomics 2011;11:935-43.

65. Wilne S, Collier J, Kennedy C, Koller K, Grundy R, et al. Presentation of childhood CNS tumours: a systematic review and metaanalysis. Lancet Oncol 2007;8:685-95.

66. Kumar A, Agrawal M, Prakash S, Somorendra S, Singh PK, et al. Acute foramen magnum syndrome following single diagnostic lumbar puncture: consequence of a small posterior fossa? World Neurosurg 2016;91:677.e1-7.

67. Nonaka T, Wong DTW. Liquid biopsy in head and neck cancer: promises and challenges. J Dent Res 2018;97:701-8.

68. Hsiao YC, Chu LJ, Chen YT, Chi LM, Chien KY, et al. Variability assessment of 90 salivary proteins in intraday and interday samples from healthy donors by multiple reaction monitoring-mass spectrometry. Proteomics Clin Appl 2018;12.

69. Nolen BM, Orlichenko LS, Marrangoni A, Velikokhatnaya L, Prosser D, et al. An extensive targeted proteomic analysis of disease-related protein biomarkers in urine from healthy donors. PLoS One 2013;8:e63368.

70. Duffy MJ. Evidence for the clinical use of tumour markers. Ann Clin Biochem 2004;41:370-7.

71. Shalaby T, Fiaschetti G, Baumgartner M, Grotzer MA. Significance and therapeutic value of miRNAs in embryonal neural tumors. Molecules 2014;19:5821-62.

72. Hao TB, Shi W, Shen XJ, Qi J, Wu XH, et al. Circulating cell-free DNA in serum as a biomarker for diagnosis and prognostic prediction of colorectal cancer. Br J Cancer 2014;111:1482-9.

73. Zhou Q, Liu J, Quan J, Liu W, Tan H, et al. MicroRNAs as potential biomarkers for the diagnosis of glioma: a systematic review and meta-analysis. Cancer Sci 2018;109:2651-9.

74. Ivo D'Urso P, Fernando D'Urso O, Damiano Gianfreda C, Mezzolla V, Storelli C, et al. miR-15b and miR-21 as circulating biomarkers for diagnosis of glioma. Curr Genomics 2015;16:304-11. 
75. Rani S, Gately K, Crown J, O'Byrne K, O'Driscoll L. Global analysis of serum microRNAs as potential biomarkers for lung adenocarcinoma. Cancer Biol Ther 2013;14:1104-12.

76. Sierzega M, Kaczor M, Kolodziejczyk P, Kulig J, Sanak M, et al. Evaluation of serum microRNA biomarkers for gastric cancer based on blood and tissue pools profiling: the importance of miR-21 and miR-331. Br J Cancer 2017;117:266-73.

77. Wang W, Li W, Ding M, Yuan H, Yang J, et al. Identification of miRNAs as non-invasive biomarkers for early diagnosis of lung cancers. Tumour Biol 2016; doi: 10.1007/s13277-016-5442-y.

78. Wen Y, Han J, Chen J, Dong J, Xia Y, et al. Plasma miRNAs as early biomarkers for detecting hepatocellular carcinoma. Int J Cancer 2015;137:1679-90.

79. Wu Q, Lu Z, Li H, Lu J, Guo L, et al. Next-generation sequencing of microRNAs for breast cancer detection. J Biomed Biotechnol 2011;2011:597145.

80. Ferretti E, De Smaele E, Miele E, Laneve P, Po A, et al. Concerted microRNA control of Hedgehog signalling in cerebellar neuronal progenitor and tumour cells. EMBO J 2008;27:2616-27.

81. Regazzo G, Terrenato I, Spagnuolo M, Carosi M, Cognetti G, et al. A restricted signature of serum miRNAs distinguishes glioblastoma from lower grade gliomas. J Exp Clin Cancer Res 2016;35:124.

82. Goto G, Hori Y, Ishikawa M, Tanaka S, Sakamoto A. Changes in the gene expression levels of microRNAs in the rat hippocampus by sevoflurane and propofol anesthesia. Mol Med Rep 2014;9:1715-22.

83. Rangaswami H, Bulbule A, Kundu GC. Osteopontin: role in cell signaling and cancer progression. Trends Cell Biol 2006;16:79-87.

84. Kao CL, Chiou SH, Ho DM, Chen YJ, Liu RS, et al. Elevation of plasma and cerebrospinal fluid osteopontin levels in patients with atypical teratoid/rhabdoid tumor. Am J Clin Pathol 2005;123:297-304.

85. Bacolod MD, Johnson SP, Ali-Osman F, Modrich P, Bullock NS, et al. Mechanisms of resistance to 1,3-bis(2-chloroethyl)-1-nitrosourea in human medulloblastoma and rhabdomyosarcoma. Mol Cancer Ther 2002;1:727-36.

86. Bacolod MD, Fehdrau R, Johnson SP, Bullock NS, Bigner DD, et al. BCNU-sequestration by metallothioneins may contribute to resistance in a medulloblastoma cell line. Cancer Chemother Pharmacol 2009;63:753-8.

87. Krizkova S, Fabrik I, Adam V, Kukacka J, Prusa R, et al. Utilizing of adsorptive transfer stripping technique brdicka reaction for determination of metallothioneins level in melanoma cells, blood serum and tissues. Sensors (Basel) 2008;8:3106-22.

88. Krizkova S, Masarik M, Majzlik P, Kukacka J, Kruseova J, et al. Serum metallothionein in newly diagnosed patients with childhood solid tumours. Acta Biochim Pol 2010;57:561-6.

89. Sobol-Milejska G, Mizia-Malarz A, Musiol K, Chudek J, Bozentowicz-Wikarek M, et al. Serum levels of vascular endothelial growth factor and basic fibroblast growth factor in children with brain tumors. Adv Clin Exp Med 2017;26:571-5.

90. Weathers SP, de Groot J. VEGF manipulation in glioblastoma. Oncology (Williston Park) 2015;29:720-7.

91. Behrends U, Schneider I, Rössler S, Frauenknecht H, Golbeck A, et al. Novel tumor antigens identified by autologous antibody screening of childhood medulloblastoma cDNA libraries. Int J Cancer 2003;106:244-51.

92. Verly IR, van Kuilenburg AB, Abeling NG, Goorden SM, Fiocco M, et al. Catecholamines profiles at diagnosis: increased diagnostic sensitivity and correlation with biological and clinical features in neuroblastoma patients. Eur J Cancer 2017;72:235-43.

93. Pricola Fehnel K, Duggins-Warf M, Zurakowski D, McKee-Proctor M, Majumder R, et al. Using urinary bFGF and TIMP3 levels to predict the presence of juvenile pilocytic astrocytoma and establish a distinct biomarker signature. J Neurosurg Pediatr 2016;18:396-407.

94. Smith ER, Zurakowski D, Saad A, Scott RM, Moses MA. Urinary biomarkers predict brain tumor presence and response to therapy. Clin Cancer Res 2008;14:2378-86.

95. Ostrom QT, Gittleman H, Truitt G, Boscia A, Kruchko C, et al. CBTRUS statistical report: primary brain and other central nervous system tumors diagnosed in the United States in 2011-2015. Neuro Oncol 2018;20:iv1-iv86.

96. Bettegowda C, Sausen M, Leary RJ, Kinde I, Wang Y, et al. Detection of circulating tumor DNA in early- and late-stage human malignancies. Sci Transl Med 2014;6:224ra24.

97. Pages M, Rotem D, Gydush G, Reed S, Rhoades J, et al. Liquid biopsy detection of genomic alterations in pediatric brain tumors from cell free DNA in peripheral blood, CSF, and urine. Neuro-Oncology 2018;20:vi142-3.

98. Spreafico F, Bongarzone I, Pizzamiglio S, Magni R, Taverna E, et al. Proteomic analysis of cerebrospinal fluid from children with central nervous system tumors identifies candidate proteins relating to tumor metastatic spread. Oncotarget 2017;8:46177-90.

99. Cengiz P, Zemlan F, Eickhoff JC, Ellenbogen R, Zimmerman JJ. Increased cerebrospinal fluid cleaved tau protein (C-tau) levels suggest axonal damage in pediatric patients with brain tumors. Childs Nerv Syst 2015;31:1313-9.

100. Murray MJ, Bell E, Raby KL, Rijlaarsdam MA, Gillis AJ, et al. A pipeline to quantify serum and cerebrospinal fluid microRNAs for diagnosis and detection of relapse in paediatric malignant germ-cell tumours. Br J Cancer 2016;114:151-62.

101. Banfield E, Brown AL, Peckham EC, Rednam SP, Murray J, et al. Exploratory analysis of ERCC2 DNA methylation in survival among pediatric medulloblastoma patients. Cancer Epidemiol 2016;44:161-6.

102. Akino T, Han X, Nakayama H, McNeish B, Zurakowski D, et al. Netrin-1 promotes medulloblastoma cell invasiveness and angiogenesis, and demonstrates elevated expression in tumor tissue and urine of patients with pediatric medulloblastoma. Cancer Res 2014;74:3716-26. 